\title{
Leadership and Gender Inclusiveness in Academic Psychiatry
}

\author{
Laura Weiss Roberts ${ }^{1}$
}

Received: 24 November 2015 / Accepted: 7 December 2015 / Published online: 29 December 2015

(C) Academic Psychiatry 2015

Nine of 10 academic departments of psychiatry in the USA are led by men, according to Doyle et al. [1] who report on a 2014 survey study of chairs in this issue of Academic Psychiatry. Men were more likely than women to lead large departments, to have stronger h-index scores (a signal of scholarship impact), to have been recruited through a national search, and to have held their leadership positions for a longer period of time. Men serving as chairs were more commonly married and had fewer children. Men identified fewer obstacles along the path to leadership, whereas women identified insufficient mentorship, gender discrimination, and family duties as barriers. For women, the main bit of good news from the study was the observation that women serving as chairs on average were younger, suggesting that there has been some recent upward movement through the "glass ceiling" in academic psychiatry.

How do we best interpret the findings from this study? It is important to look at the results first in light of the greater context of the physician and physician-in-training workforce in the USA. The Association of American Medical Colleges (AAMC) recently commissioned an analysis to assess and project physician workforce needs, finding that women comprise close to one third (31\%) of the overall physician workforce [1]. Of physicians who were in their 50s and 60s, however, women represented less than one quarter of the workforce. In residency and fellowship positions overall, women have $46 \%$ of the slots - they are most highly represented in primary care fields and least represented in highly competitive procedural areas, such as orthopedic surgery. In psychiatry, men have outnumbered women in the field historically,

Laura Weiss Roberts

LWRoberts.EIC@gmail.com

1 Stanford University School of Medicine, Stanford, CA, USA although recently the number of women entering the disciplines of psychiatry and child and adolescent psychiatry has grown, with 54 and $61 \%$ women matching in these roles in 2013 [2]. Taken in context, then, one might expect that two of three academic departments of psychiatry would be led by men - not 9 of 10 - and that, in time, women will increasingly be placed in the role of chair.

In absolute numbers, more women have been appointed as chairs since the time of the Doyle et al. study. In October 2015, 21 of $148(14 \%)$ of all academic departments of psychiatry listed with the AAMC were led by women in permanent $(n=$ $16)$ or interim $(n=5)$ chair positions (personal communication). The number of medical schools continues to increase, however, so there is still quite a distance to travel before the proportion of women in top academic psychiatry leadership roles reflects the underlying proportion of women in the field.

A recent study of women in higher education [3] found that women constituted a larger share of faculty at community colleges $(53 \%)$ and bachelors/masters-degree granting institutions $(45 \%)$ than at doctoral-degree granting institutions (38\%). Women leading as presidents and chief academic officers were not proportional to the underlying base population of female faculty at each kind of institution, however. The authors interviewed 35 women with senior-level leadership roles in higher education and identified several barriers to leadership, including different expectations for men and women, discouragement and sabotage by colleagues, lack of opportunity and support, and not having a leadership identity. These issues were endorsed more, overall, for underrepresented minority women in the study.

Negative aspects of leadership roles identified by women engaged in this study included the time demands of the positions, scrutiny and criticism, the feeling of pressure for ultimate accountability, personal and professional isolation, the broad scope of the job, and a sense of not fitting or not being 
"heard" in one's role. Supports to leadership included the experience of encouragement and support, formal development and early leadership experiences, and having a role model. The women leaders in this project endorsed having an impact or influence, having authority and autonomy, and serving as a role model as key positives associated with leadership positions. Whereas many of these reflections would be similar for men and for women in such roles, it may well be that certain experiences, such as lacking role models and isolation, are greater for women.

The chairs study conducted by Doyle et al. [4] has value in terms of its focus on an important set of issues related to gender and leadership in the field of academic psychiatry. Their approach has limitations in that they queried members of the American Association of Chairs of Departments of Psychiatry rather than the full base population of women in academic psychiatry chair positions. Their survey instrument was newly developed for this project. Their analytic approach of comparing the responses from women serving as chairs to a subset of men in that role may have introduced bias. Certain observations, such as the higher h-index of men who were chairs, could be related to age rather than to gender, because women in the study tended to be younger. For these reasons, their findings should be viewed as preliminary and as the basis for further inquiry.

Beyond the issue of women in visible leadership roles in academic psychiatry is, in my view, the greater issue of inclusiveness in medicine. The paper by Doyle and colleagues should challenge us to examine the phenomenon of whiteness in medicine; the lack of socioeconomic diversity in the backgrounds of our medical students, residents, and faculty; and the obstacles to leadership roles experienced by members of other underrepresented groups, such as immigrant and firstgeneration physicians and members of the lesbian, gay, bisexual, transgender, and questioning community. To illustrate, in August 2015, the AAMC [5] released a report indicating that the number of African American men applying to medical school dropped from 1410 in 1978 to 1337 in 2014. The number of African American male medical students who enrolled as first-year students in 1978 was 515 and increased only modestly to 542 in this same time period, despite the dramatic increase in the number of positions for entering medical students. Overall, among 85,260 students enrolled in US medical schools in 2014, only 205 (0.2\%) were American Indian or Alaska Native; 3444 (4\%) were Hispanic, Latino, or of Spanish origin; and 5335 (6\%) were Black or African American. Hispanic people are the largest minority group in the USA, making up $17 \%$ of the population [6]. There is much, much work to be done.

In conclusion, women are certainly underrepresented among chairs of academic departments of psychiatry, as they are in leadership positions across other areas of academic medicine and higher education. Women who have attained leadership roles, as with other underrepresented groups, have encountered and overcome many barriers - perhaps more and different obstacles than their male counterparts, as the Doyle et al. study suggests. The absence of mentorship and role models and the presence of significant family responsibilities are recurrent themes in studies of women and leadership. Providing mentorship experiences and connecting great mentors with talented individuals with leadership capacities are feasible efforts, as are nurturing, elevating, and making visible excellent role models for aspiring leaders. Creating more services, such as child care, elder care, and home care, to help leaders manage their many family commitments is also feasible. More challenging, however, are reports throughout the literature of overt discrimination and of behavior that undermines or sabotages the efforts of women who aspire to leadership roles. Such conduct is damaging and difficult to address, and yet reversing this pattern of behavior is very important to individuals and institutions endeavoring to engage in their best work.

Many women in leadership roles are still outliers-women who are themselves extraordinary or who have found themselves in extraordinary circumstances, or both, and who have found their path into positions of influence, accountability, and responsibility. These women possess many strengths and shoulder much. Many have sacrificed a great deal in their lives of professional service, including their service as leaders. As the number of individuals from diverse backgrounds increases and the proportion of underrepresented groups in academic psychiatry becomes more balanced, my hope is that the pathways to leadership will become less distorted by the influence of prejudice and will become more inclusive. I hope that mentors and role models will become more plentiful and that institutions will invest in creating opportunities and supports to all individuals with leadership potential. I further hope that it will become a normative expectation that all who enter our field will and should become leaders - not that they are disrupting or defying the traditions of academic psychiatry by doing so.

\section{Compliance with Ethical Standards}

Disclosure The author states that there is no conflict of interest.

\section{References}

1. IHS Inc. The complexities of physician supply and demand: projections from 2013 to 2025. Prepared for the Association of American Medical Colleges. Washington, DC, Association of American Medical Colleges, 2015

2. Association of American Medical Colleges Center for Workforce Studies. 2014 Physician specialty data book. November 2014. Washington, DC, Association of American Medical Colleges, 2014 
3. Hannum K, Muhly S, Shockley-Zalabak P, White JS. Stories from the summit trail: Leadership journeys of senior women in higher education. Denver, CO, Higher Education Resource Services (HERS). 2014. Available at http://hersnet.org/wp-content/uploads/ 2014/07/StoriesfromtheSummitTrail.pdf. Last accessed 24 November 2015

4. Doyle M, Pederson A, Meltzer-Brody S. Demographic and personal characteristics of male and female chairs in academic psychiatry. Acad Psychiatry. 2015. doi: 10.1007/s40596-0150408-8
5. Association of American Medical Colleges. Altering the course: Black males in medicine. Washington, DC, Association of American Medical Colleges, 2015. Available at https://www.aamc. org/download/439660/data/20150803_alteringthecourse.pdf. Last accessed 24 November 2015

6. Association of American Medical Colleges. FACTS: applicants, matriculants, enrollment, graduates, $\mathrm{MD} / \mathrm{PhD}$, and residency applicants data. Table 31: Total enrollment by U.S. medical school and race/ethnicity, 2014. Available at https://www.aamc.org/data/facts/. Last accessed 24 November 2015. 